\title{
The effect of developmental stage on eggshell thickness variation in endangered falcons
}

\author{
Aurora M. Castilla ${ }^{\mathrm{a}, *}$, Anthony Herrel ${ }^{\mathrm{b}}$, Hugo Robles ${ }^{\mathrm{c}, \mathrm{d}}$, Jim Malone ${ }^{\mathrm{e}}$, Juan José Negro ${ }^{\mathrm{a}}$ \\ ${ }^{a}$ Estación Biológica de Doñana, Agencia Estatal Consejo Superior de Investigaciones Científicas (CSIC), C/Americo Vespucio s/n, 41092 Sevilla, Spain \\ b UMR 7179 C.N.R.S/M.N.H.N. Département d’Ecologie et de Gestion de la Biodiversité, 57 rue Cuvier, Case postale 55, 75231, Paris Cedex 5, France \\ ${ }^{\mathrm{c}}$ Evolutionary Biology Group (GIBE), Faculty of Sciences, University of A Coruña, Campus Zapateira, 15008 A Coruña, Spain \\ d Evolutionary Ecology Group (EVO-ECO), Department of Biology, University of Antwerp, Middelheimcampus, Groenenborgerlaan 171, BE-2020 Antwerp, Belgium \\ ${ }^{\mathrm{e}}$ Information Services Librarian, Weill Cornell Medical College in Qatar, P.O. Box 24144, Doha, State of Qatar, Qatar
}

Keywords:

Avian raptor

Egg laying sequence Eggshell

thinning Environmental

contamination

\begin{abstract}
a b s t r a c t
We compared eggshell thickness of hatched eggs with that of non-developed eggs in endangered falcon taxa to explore the effect of embryo development on eggshell thinning. To our knowledge, this has never been examined before in falcons, despite the fact that eggshell thinning due to pollutants and environmental contamination is often considered the most common cause of egg failure in falcons. Because of the endangered nature of these birds, and the difficulty in gaining access to the nests and their eggs, there is a large gap in our knowledge regarding eggshell thickness variation and the factors affecting it. We used a linear mixed-effects (LME) model to explore the variation in eggshell thickness ( $n=335$ eggs) in relation to the developmental stage of the eggs, but also in relation to the falcon taxa, the laying sequence and the study zone. Female identity $(n=69)$ and clutch identity $(n=98)$ were also included in the LME model. Our results are consistent with the prediction that eggshell thickness decreases during incubation because of the important effect of calcium uptake by the embryo during development. Our results also show that eggs laid later in the sequence had significantly thinner eggshells. In this study, we provide the first quantitative data on eggshell thickness variation of hatched eggs in different falcon taxa that were not subjected to contamination or food limitation (i.e., bred under captive conditions). Because eggshell thickness strongly influences survival and because the species examined in this study are endangered, our data represent a valuable control for future studies on the effects of pollution on eggshells from wild populations and thus are an important contribution to the conservation of falcons.
\end{abstract}

\section{Introduction}

The main functions of the eggshell in birds are protection, and gas and water exchange. In addition, the eggshell provides the embryo with minerals and calcium needed for the development of calcium consuming organs including the skeleton, muscles and brain (Tuan et al., 1991; Blom and Lilja, 2004; Wilkin et al., 2009). Thus, the avian egg provides the developing embryo with an ideal environment for development (Romanoff and Romanoff, 1949; Rahn and Ar, 1974; Solomon, 1991).

Despite the considerable body of research devoted to eggshell characteristics, either in poultry science (Hunton, 1995; Carnarius et al., 1996) or in wild birds (Massaro and Davis, 2004, 2005; Castilla et al., 2007, 2009b), the effect of developmental stage

\footnotetext{
* Corresponding author at: Estación Biológica y de Cultura Científica de Sanaüja, Ap. Correos $n^{\circ}$ 35, 25280 Solsona, Lleida, Spain. Tel.: +34 687536411 ; fax: +34973480431 .

E-mail address: castilla@ebd.csic.es (A.M. Castilla).
}

on eggshell thickness or strength remains unknown for most wild species. Since developing embryos utilize calcium from the eggshell, developmental stage can be expected to cause eggshell thinning (Vanderstoep and Richards, 1970; Bunck et al., 1985; Bennett, 1995; Castilla et al., 2007; Karlsson and Lilja, 2008). Additionally, eggshell thickness appears to be influenced by many factors including genetics, egg colour and size, the time the eggs spend in the uterus, female characteristics (condition, age, stress, health status), and the diet of the females (Kennedy and Vevers, 1973; Nys et al., 1991; Francesch et al., 1997; Ciftci et al., 2003; Boersma et al., 2004; Riczu et al., 2004; Castilla et al., 2007, 2009b; Birchard and Deeming, 2010). More recent studies have shown that Mycoplasma infection also produced egg abnormalities and eggshell thinning (Feberwee et al., 2009).

Because of the endangered nature of many raptor species (Cramp and Simmons, 1980), eggshell thinning has been the focus of much research in these species (Cade et al., 1971; Peakall and Lincer, 1996; Falk et al., 2006; Castilla et al., 2009b). Population collapse and reproductive failure in raptors have occurred in many parts of the northern hemisphere from about 1950 onwards, and 

have often been attributed to the use of biocides in agriculture and forestry management (Wegner et al., 2005; Falk et al., 2006; Fernie et al., 2009). Accumulation of toxic persistent compounds causes eggshell thinning and reduction in eggshell strength in eggs laid by falcons and other bird species exposed to toxins (Bunck et al., 1985; Peakall and Lincer, 1996; Falk et al., 2006; Kamata et al., 2006; Jagannath et al., 2008). Falcons are important bird indicator species as they are extremely vulnerable to insecticides and contamination. Consequently, their eggshells are considered to be good indicators of pollution and can be used to monitor the health of populations over long periods (Falk et al., 2006; Castilla et al., 2009a).

To our knowledge, the effect of developmental stage on eggshell thickness variation in falcons has never been examined before. This is remarkable, since pollutants and environmental contamination are often considered the most common cause of egg failure. Yet, without knowing how eggshell thickness is affected by development, a natural process that reduces eggshell thickness, interpretations of other studies on eggshell thickness remain difficult. Because of the difficulty in gaining access to the nests and their eggs, there is a large gap in our knowledge regarding eggshell thickness variation and the factors affecting it.

In this study we therefore examined the effect of developmental stage on eggshell thickness variation in different falcon taxa. We tested the prediction that eggshells from non-developed eggs are thicker than those of hatched eggs. We also tested the prediction that eggs produced later in the laying sequence have thinner shells than eggs laid first.

\section{Materials and methods}

\subsection{Study animals and eggs}

The falcon species examined in this study are protected, rare or endangered and they are included on the CITES list (Tucker and Heath, 1994). Studied species include the peregrine falcon (Falco peregrinus peregrinus; P), the red shaheen falcon (Falco peregrinus babylonicus; $\mathrm{B}$ ); the intraspecific hybrid peregrine $\times$ red shaheen $(\mathrm{F}$. p. peregrinus $\times$ F. p. babylonicus; $P B$ ); the saker falcon (Falco cherrug; $\mathrm{C}$ ), the gyr falcon (Falco rusticolus; R), and the interspecific hybrid between the saker falcon and the gyr falcon (Falco cherrug $\times$ Falco rusticolus; CR). We did not have access to fully developed F. rusticolus eggs.

Females show large differences in body size (ranging from 600 to $1800 \mathrm{~g}$ ) depending on the taxon (Cramp and Simmons, 1980). In the present study, body mass was measured at the end of summer after reproduction was finished. The birds were captured in their cages and weighed with an electronic balance (Krups 840; Krups, Offenbach/Main, Germany) to the nearest gram.

The eggs were obtained from two different breeding falcon farms in Catalonia (NE Spain) that were not subjected to agricultural or industrial pollution. One facility was near the coast at $97 \mathrm{~m}$ above sea level (mean annual temperature: $14{ }^{\circ} \mathrm{C}$, mean annual precipitation: $650 \mathrm{~mm}$, mean relative humidity: $80 \%$ ); the other one was in the Pyrenees Mountains at $800 \mathrm{~m}$ above sea level (mean annual temperature: $12{ }^{\circ} \mathrm{C}$, mean annual precipitation: $650 \mathrm{~mm}$, mean relative humidity: $65 \%$ ).

Falcons are bred world-wide and are a common target for conservation programs. This provides a unique opportunity since a large sample of eggs can be obtained for scientific research. Moreover, falcons in captive breeding facilities are bred under optimal conditions and fed high-quality food. Since all taxa and individuals were housed and fed similarly, results can be compared without bias in that respect.

We examined 98 clutches from 69 different females (total of 161 non-developed and 174 developed eggs) that were collected between March and July 2007. In the field, the falcon species studied here typically lay one clutch of 4-6 eggs and have an incubation period that lasts ca. 25-30 days (Cramp and Simmons, 1980). Eggpulling (i.e., removing eggs as they are laid) was conducted in both zones, so females did not produce true clutches as they would do in the wild. However, most females produced between 4 and 9 eggs. Data on egg laying sequence was obtained by writing down consecutive numbers on the eggshells as the female was laying the eggs. The eggshells of hatched chicks were obtained from the birth rooms.

We used an ovoscope and direct observations after egg breakage to establish two developmental categories: eggs with nondeveloped embryos (i.e., infertile or aborted during the first week of incubation), and developed eggs (i.e., hatched eggs or aborted eggs with fully developed embryos). Egg mass was measured (to $0.01 \mathrm{~g}$ ) with an electronic balance (Sartorius AG, Goettingen, Germany) in fresh eggs that were recently laid.

Eggshell thickness measurements were conducted in three equidistant locations around the equator of the egg, using a micrometer (Mitutoyo, Mizonokuchi, Japan), to the nearest $0.001 \mathrm{~mm}$. The average was calculated to obtain an overall indicator of eggshell thickness. When possible, measurements were taken from the pale spots of the egg in order to reduce variation of thickness due to differences in pigmentation (see Gosler et al., 2005). All measurements were conducted without the membrane, since membranes are rather thick in falcon eggs (Castilla et al., 2009b). The outer thick eggshell membrane and the thin vascularized chorioallantoic membrane were removed from the eggshells after immersing them in water (see Castilla et al., 2010).

\subsection{Statistics}

The influence of the developmental stage of the eggs on eggshell thickness was examined using a linear mixed-effects (LME) model (Pinheiro and Bates, 2000). The LME model was fitted with the "Ime" function in S-Plus 2000 (MathSoft, Inc., Seattle, WA, USA) and model parameters were estimated with restricted maximum likelihood. Mixed models allow both fixed and random terms to be fitted (Shall, 1991). Random terms in our model take into consideration multiple measurements within the same clutches and females. Thus, clutch identity was nested within female identity, and female identities were fitted as random terms. The developmental stage of the eggs was fitted as a fixed term. In addition, we also fitted as fixed terms the falcon species, the laying sequence and the breeding area, since they may also influence eggshell thickness.

We additionally explored the relationships between female body mass and the average eggshell thickness for eggs with different developmental stages for each taxon separately. We used Pearson correlations of individual means (SPSS V. 15). In all cases, the P-value used to denote significance was 0.05.

\section{Results}

Overall, we found a large and significant variation in eggshell thickness among taxa. Eggs of the peregrine falcons $(\mathrm{P}, \mathrm{B}, \mathrm{PB})$ had thinner eggshells than those of the larger falcon species (i.e., C, $\mathrm{R}, \mathrm{CR}$ ) independent of developmental stage (ANOVA, developed: $\mathrm{F}_{1,208}=152.54, \mathrm{P}<0.001$; undeveloped: $\mathrm{F}_{1,167}=122.19, \mathrm{P}<0.001$; Fig. 1). Within the larger falcons no differences were found between taxa irrespective of development (ANOVA, $\mathrm{F}_{2,184}=1.54$; $\mathrm{P}=0.22)$. However, within the peregrines, F. p. peregrinus showed the thickest eggshells irrespective of developmental stage (ANOVA, $F_{2,189}=25.78 ; \mathrm{P}<0.001$; Fig. 1). We also found a large difference among taxa in the proportion of eggshell decrease during development (Table 1). 


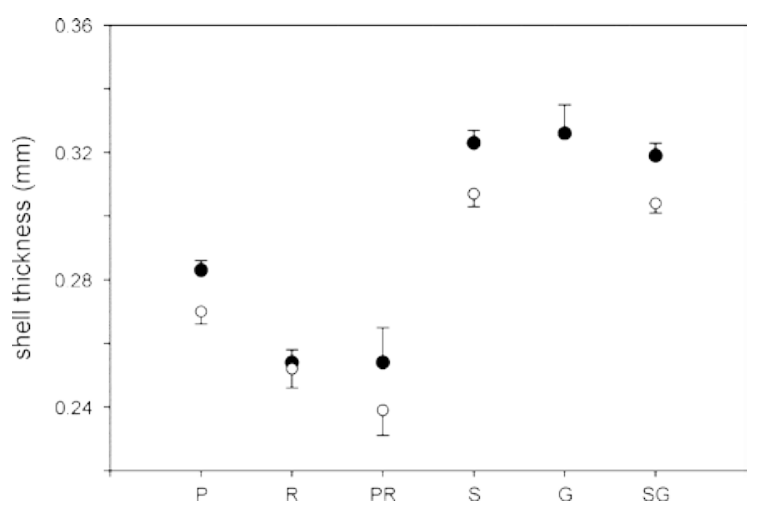

Fig. 1. Shell thickness (mean $\pm \mathrm{SE}$ ) of eggs of different developmental stage (black = undeveloped, white $=$ fully developed) for the different falcon species . $\mathrm{P}=$ peregrine falcon (Falco peregrinus peregrinus, $\mathrm{R}=$ red shaheen falcon (Falco peregrinus babylonicus), $\mathrm{PR}=$ intraspecific hybrid peregrine $\times$ red shaheen $(\mathrm{F}$. p. peregrinus $\times$ F. p. babylonicus), $S=$ saker falcon (Falco cherrug), $G=$ gyr falcon (Falco rusticolus), $S G=$ interspecific hybrid saker $\times$ gyr $(F$. cherrug $\times$ F. rusticolus $)$.

\section{Table 1}

Mean ( \pm SE) eggshell thickness $(\mathrm{mm})$ of eggs with non-developed embryos or with fully developed embryos in different falcon taxa. Also indicated is the decrease in mean thickness (in \%) during development for each taxon. $\mathrm{P}=$ peregrine falcon (Falco peregrinus peregrinus), $\mathrm{R}=$ red shaheen falcon (Falco peregrinus babylonicus), $\mathrm{PR}=$ intraspecific hybrid peregrine $\times$ red shaheen (F. p. peregrinus $\times$ F. p. babylonicus), $\mathrm{S}=$ saker falcon (Falco cherrug), $\mathrm{SG}=$ interspecific hybrid saker $\times \operatorname{gyr}(\mathrm{F}$. cherrug $\times \mathrm{F}$. rusticolus).

\begin{tabular}{|c|c|c|c|c|c|c|c|}
\hline & \multicolumn{3}{|c|}{ Non-developed eggs } & \multicolumn{3}{|c|}{ Developed eggs } & \multirow[t]{2}{*}{ \% Decrease } \\
\hline & Mean & SE & $\mathrm{n}$ & Mean & SE & $\mathrm{n}$ & \\
\hline $\mathrm{P}$ & 0.2840 & 0.0036 & 67 & 0.2704 & 0.0045 & 38 & 4.79 \\
\hline $\mathrm{R}$ & 0.2550 & 0.0038 & 34 & 0.2509 & 0.0043 & 20 & 1.61 \\
\hline PR & 0.2413 & 0.0066 & 5 & 0.2391 & 0.0027 & 10 & 0.91 \\
\hline S & 0.3205 & 0.0046 & 29 & 0.3063 & 0.0043 & 38 & 4.43 \\
\hline SG & 0.3184 & 0.0039 & 39 & 0.3061 & 0.0041 & 55 & 3.86 \\
\hline
\end{tabular}

The LME model showed that eggshell thickness was significantly affected by the developmental stage of the eggs (Table 2, Fig. 1). Eggs with fully developed embryos had thinner shells than eggs with non-developed embryos (estimate $\pm \mathrm{SE}=-0.005 \pm 0.001$ ). In addition, eggshell thickness was significantly affected by the laying sequence (Table 2). The negative sign of the parameter estimate (estimate $\pm \mathrm{SE}=-0.002 \pm 0.001$ ) indicates that eggs laid later in the laying sequence had lower eggshell thickness (Table 2). The breeding farm, however, had no influence on the observed variation in eggshell thickness among species (Table 2). The two-way interactions of all fixed terms were not significant (all $\mathrm{P}>0.1$ ). Thus, the same trend of eggshell thinning associated with developmental stage was present in all taxa (Fig. 2). The non-significant interaction of all fixed terms indicates that the decrease of eggshell thickness throughout the laying sequence is common to all taxa.

The effect of the mass of the eggs was marginally significant (Table 2). Heavier eggs tended to have thicker shells (estimate $\pm \mathrm{SE}=0.0008 \pm 0.0004)$. The relationships between female

\section{Table 2}

Linear mixed-effects analysis examining the variation in eggshell thickness $(n=335$ eggs) in relation to the developmental stage of the eggs, the falcon taxa, the laying sequence and the zone. Female identity $(n=69)$, and clutch identity $(n=98)$ nested within female identity were fitted as random terms.

\begin{tabular}{llll}
\hline Model factors & $\mathrm{F}$ & d.f. & $\mathrm{P}$ \\
Developmental stage & 25.92 & 1,233 & 0.0001 \\
Taxa & 24.14 & 4,63 & 0.0001 \\
Laying sequence & 15.27 & 1,233 & 0.0001 \\
Egg mass & 3.48 & 1,233 & 0.063 \\
Zone & 1.8 & 1,63 & 0.185 \\
\hline
\end{tabular}

body mass and eggshell thickness for eggs with different developmental stages were non-significant for most taxa. Only in the case of the interspecific hybrid saker $\times$ gyr (F. cherrug $\times$ F. rusticolus) the relationships approached significance (undeveloped: $R^{2}=0.20$; $\mathrm{F}_{1,15}=3.84 ; \mathrm{P}=0.069$; developed: $\mathrm{R}^{2}=0.32 ; \mathrm{F}_{1,15}=7.16 ; \mathrm{P}=0.017$; dashed lines in Fig. 2).

\section{Discussion}

In this study we provide the first quantitative data on eggshell thickness variation of hatched eggs in different falcon taxa that were not subjected to contamination or food limitation (i.e., bred under captive conditions), allowing our data to be used as a reference for studies on eggs from natural populations. Our results are consistent with the prediction that eggshell thickness decreases during incubation, and suggest that the effects of calcium uptake by the embryos are as important in falcon taxa as they are in other bird taxa.

We found large differences among taxa in the proportion of eggshell thickness decrease during development (from 1\% to 5\%). However, these results should be interpreted cautiously because each individual egg was measured only once. Despite this limitation, our data do show that the proportion of eggshell thickness decrease is not correlated with egg or female mass. Because calcium removal from the eggshell is used by the embryo during the formation of the skeleton, one could expect higher rates of eggshell removal in species with a higher intrinsic demand for calcium. However, since under captive conditions food and calcium are not limiting, effects of differences in food quality cannot explain the observed patterns. Higher intrinsic demands, as could be expected for larger species, also do not appear to explain the differential decrease in eggshell thickness in the taxa examined here.

Prior studies have shown that growth rate may play a fundamental role in the pattern of skeletal development in birds: the faster the growth, the less ossified the skeleton is at hatching (Bond et al., 1988; Karlsson and Lilja, 2008). In a comparative study including 36 bird species from 18 orders (ranging from Struthioniformes to Passeriformes), it has been shown that slow-growing (precocial; e.g., partridges) and fast-growing species (altricial; e.g., passerines) lay eggs encased in shells with different structures adapted to support different rates of calcium removal by developing embryos (Karlsson and Lilja, 2008). Moreover, calcium removal was more extensive in shells from precocial birds than in shells from altricial birds (Karlsson and Lilja, 2008). Interestingly, falcons are semiprecocial birds (i.e., mixed altricial and precocial traits), and thus we expected similar rates of calcium removal among the five studied taxa. Clearly, further studies investigating the uptake and allocation of eggshell-derived calcium are needed to be able to address this issue.

The available literature for eggshell reduction during development typically refers to either eggshell thickness or egg hardness. However, because both variables are correlated to some degree (Castilla et al., 2007, 2009b), we compared our data with examples from other studies, irrespective of the measurements taken. Precocial species showed decreases as follows: Coturnix japonica ( $7 \%$, Kreitzer, 1972; or 19-33\%, Castilla et al., 2007), Anas platyrhynchos (15-22\%, Bennett, 1995), Colinus virginianus (17\%, Bennett, 1995), Alectoris rufa (24\%, Castilla et al., 2007). However, differences of 3-5 days in incubation time in the same species resulted in differences in the proportion of eggshell reduction during development of $14 \%$ and $7 \%$ for C. japonica (Castilla et al., 2007) and A. platyrhynchos (Bennett, 1995), respectively. Thus, incubation time is an important factor to consider when trying to explain the observed differences in the overall percentage of shell thickness reduction across and within species. Unfortunately, we have no data for the incubation 

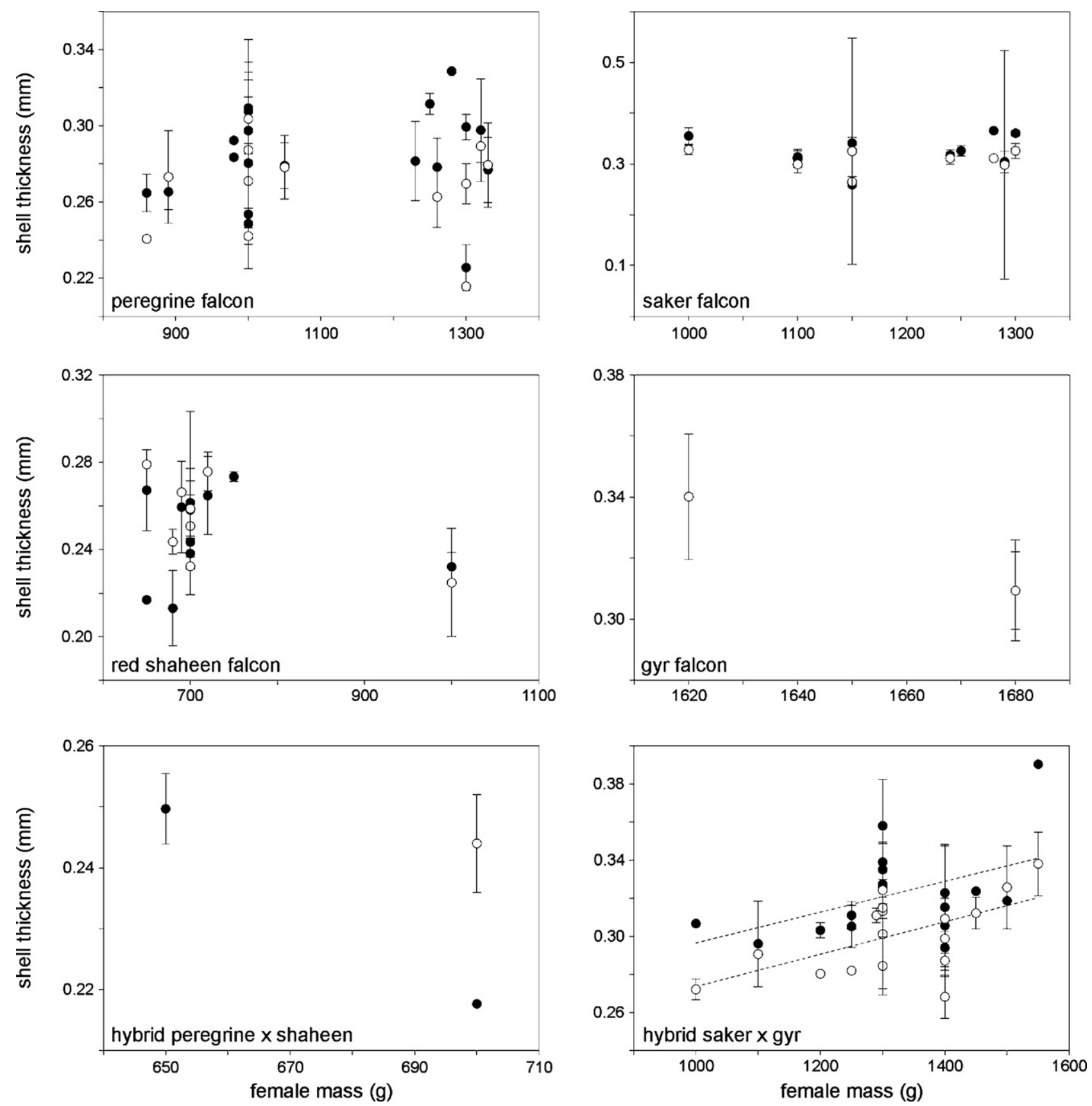

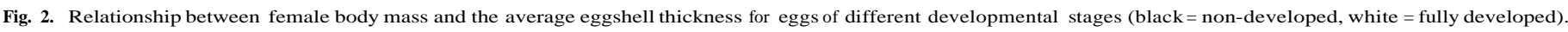

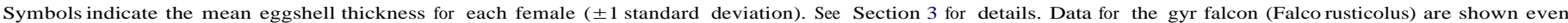
though non-developed eggs were not available.

period of the falcons studied here. However, the available data in the literature indicate a similar period of 28-33 days for the small peregrines as well as the big saker and gyr falcons (Harrison, 1982).

It is important, however, to point out that some authors did not find a decrease in thickness during development while they did for egg strength in the same species (Bennett, 1995). More modern and non-destructive methods (e.g., ultrasound testing) should be used to conduct eggshell measurements on site before and after egg incubation in order to improve our knowledge on factors affecting percentages of calcium removal by birds during development.

Although the progressive absorption of calcium by the embryo and the decrease of eggshell hardness likely facilitate the breaking of the eggshell by hatchlings, it may also imply that eggs are more vulnerable to breakage and predation at the end of the incubation period compared to when the eggs have just been laid. Differences in eggshell thickness during incubation could be compensated for by an increase in parental care. It is known that in species with structurally weaker eggs, paternal nest defence is more extensive than in species with harder eggs (Picman and Honza, 2002). Nest predation is not considered a major cause of nest failure in falcons (Cramp and Simmons, 1980; Tucker and Heath, 1994), because falcons typically construct their nests on cliffs and rocky areas. However, because of the characteristics of the sites chosen for nest construction, egg breakage is likely to occur. Thus, the decrease of shell thickness during development is likely compensated for by other structural means. This needs to be investigated further.

In our study we also found that eggs produced later in the laying sequence had thinner shells. Our results are consistent with 
our previous study where we used a smaller sample of only nondeveloped and infertile falcon eggs (Castilla et al., 2009b). For the present study we were able to measure clutches of females that included infertile and hatched eggs. Our results are also consistent with results from other authors who observed a decreasing mean shell thickness in later clutches of captive peregrine falcons (Burnham et al., 1984; Falk and Møller, 1990).

Eggshell thickness of field eggs constitutes a valuable measurement regarding the quality of the habitat (e.g., calcium availability) or the environment (e.g., presence of persistent organic pollutants). Based on our data, researchers and field naturalists should be able to identify the origin of the eggs (whether infertile, aborted or hatched) when collecting small pieces of eggshells from the falcon nests. This could avoid erroneous interpretations of eggshell thinning in some cases.

Because eggshell thickness strongly influences survival and because the species examined in this study are endangered, our data represent a valuable control for future studies on the effects of pollution on eggshells from wild populations and thus are an important contribution to the conservation of falcons.

\section{Acknowledgements}

We would like to acknowledge the persons in charge and the workers of Roc Falcon, especially Harald Kuespert, Stania Kuespert, Oscar Oliva Piferrer and Sandor Sebestyen, for providing detailed information about the falcons, for helping to collect the eggs and measuring the birds. We are grateful to Benno Böer (UNESCO Office Doha, Qatar) for his support and encouragement to improve our knowledge about the biology and conservation of endangered falcons, and to Eusebio Jiménez Arroyo for continuous encouragement. We also gratefully acknowledge the comments provided by an anonymous referee. This work was conducted on a contract of the Spanish National Research Council (Agencia Estatal Consejo Superior de Investigaciones Científicas, CSIC) (to AMC), with the logistic support of the Ayuntamiento de Sanaüja, and by the Project Grant MICIIN-CGL 2009-10652.

\section{References}

Bennett, R.S., 1995. Relative sensitivity of several measures of eggshell quality to the stage of embryonic development. Bull. Environ. Contam. Toxicol. 54, 428-431.

Birchard, G.F., Deeming, D.C., 2010. Avian eggshell thickness: scaling and maximum body mass in birds. J. Zool. Lond. 279, 95-101.

Blom, J., Lilja, C., 2004. A comparative study of growth, skeletal development and eggshell composition in some species of birds. J. Zool. Lond. 262, 361-369.

Boersma, P.D., Rebstock, G.A., Stokes, D.L., 2004. Why penguin eggshells are thick. Auk 121, 148-155.

Bond, G.M., Board, R.G., Scott, V.D., 1988. A comparative study of changes in the structure of avian eggshells during incubation. Zool. J. Linn. Soc. 92, 105-113.

Bunck, C.M., Spann, J.W., Pattee, O.H., Fleming, W.J., 1985. Changes in eggshell thickness during incubation: implications for evaluating the impact of organochlorine contaminants on productivity. Bull. Environ. Contam. Toxicol. 35, 173-182.

Burnham, W.A., Enderson, J.H., Boardman, T.J., 1984. Variation in peregrine falcon eggs. Auk 101, 578-583.

Cade, T.J., Lincer, J.L., White, C.M., Roseneau, D.G., Swartz, L.G., 1971. DDE residues and eggshell changes in Alaskan falcons and hawks. Science 172, 955-957.

Castilla, A.M., Herrel, A., Díaz, G., Francesch, A., 2007. Developmental stage affects eggshell breaking strength in two ground-nesting birds: the partridge (Alectoris rufa) and the quail (Coturnix japonica). J. Exp. Zool. 307A, 471-477.

Castilla, A.M., Martínez de Aragón, J., Herrel, A., Møller, S., 2009a. Eggshell thickness variation in red-legged partridge (Alectoris rufa) from Spain. Wilson J. Ornithol. 121, 167-170.

Castilla, A.M., Herrel, A., Van Dongen, S., Furio, N., Negro, J., 2009b. Determinants of egg shell strength in endangered raptors. J. Exp. Zool. 311A, 303-311.

Castilla, A.M., Van Dongen, S., Herrel, A., Francesch, A., Martínez de Aragón, J., Malone, J., Negro, J.J., 2010. Increase in membrane thickness during development compensates for eggshell thinning due to calcium uptake by the embryo in falcons. Naturwissenschaften 97, 143-151.
Carnarius, K.M., Conrad, K.M., Mast, M.G., MacNeil, J.H., 1996. Relationship of eggshell ultrastructure and shell strength to the soundness of shell eggs. Poult. Sci. 75, 656-663.

Ciftci, I., Yenice, E., Eleroglu, H., 2003. Use of triticale alone and in combination with wheat or maize: effects of diet type and enzyme supplementation on hen performance, egg quality, organ weights, intestinal viscosity and digestive system characteristics. Anim. Feed Sci. Technol. 105, 149-161.

Cramp, S., Simmons, K.E.L. (Eds.), 1980. Handbook of the Birds of Europe, the Middle East and North Africa. The Birds of the Western Palaearctic, vol. 2. Oxford University Press, Oxford, UK.

Falk, K., Møller, S., 1990. Clutch size effects on eggshell thickness in the peregrine falcon and European kestrel. Ornis Scand. 21, 265-269.

Falk, K., Møller, S., Mattox, W., 2006. A long-term increase in eggshell thickness of Greenlandic peregrine falcons Falco peregrinus tundrius. Sci. Total Environ. 355, 127-134.

Feberwee, A., de Wit, J.J., Landman, W.J.M., 2009. Induction of eggshell apex abnormalities by Mycoplasma synoviae: field and experimental studies. Avian Pathol. 38, 77-85.

Fernie, K.J., Shutt, L., Letcher, R.J., Ritchie, I.J., Bird, D.M., 2009. Environmentally relevant concentrations of DE-71 and HBCD alter eggshell thickness and reproductive success of American kestrels. Environ. Sci. Technol. 43, 2124-2130.

Francesch, A., Estany, J., Alfonso, L., Iglesias, M., 1997. Genetic parameters for egg number, egg weight and eggshell color in three Catalan poultry breeds. Poult. Sci. 76, 1627-1631.

Gosler, A.G., Higham, J.P., Reynolds, J., 2005. Why are birds’ eggs speckled? Ecol. Lett. 8, 1105-1113.

Harrison, C., 1982. An Atlas of the Birds of the Western Palaearctic. Princeton University Press, Princeton, NJ.

Hunton, P., 1995. Understanding the architecture of the egg-shell. World's Poult. Sci. J. 51, 141-147.

Jagannath, A., Shore, R.F., Walker, L.A., Ferns, P.N., Gosler, A.G., 2008. Eggshell pigmentation indicates pesticide contamination. J. Appl. Ecol. 45, 133-140.

Kamata, R., Takahashi, S., Shimizu, A., Shiraishi, F., 2006. Avian transgenerational reproductive toxicity test with in ovo exposure. Arch. Toxicol. 80, 846-856.

Karlsson, O., Lilja, C., 2008. Eggshell structure, mode of development and growth rate in birds. Zoology 111, 494-502.

Kennedy, G.Y., Vevers, H.G., 1973. Eggshell pigments of the arauco fowl. Comp. Biochem. Physiol. 44B, 11-25.

Kreitzer, J.F., 1972. The effect of embryonic development on the thickness of the eggshells of Coturnix quail. Poult. Sci. 51, 1764-1765.

Massaro, M., Davis, L.S., 2004. The influence of laying date and maternal age on eggshell thickness and pore density in yellow-eyed penguins. Condor 106, 496-505.

Massaro, M., Davis, L.S., 2005. Differences in egg size, shell thickness, pore density, pore diameter and water vapour conductance between first and second eggs of snares penguins Eudyptes robustus and their influence on hatching asynchrony. Ibis $147,251-258$.

Nys, Y., Zawadzki, J., Gautron, J., Mills, A.D., 1991. Whitening of brown-shelled eggs: mineral composition of uterine fluid and rate of protoporphyrin deposition. Poult. Sci. 70, 1236-1245.

Peakall, D.B., Lincer, J.L., 1996. Do PCBs cause eggshell thinning? Environ. Pollut. 91, 127-129.

Picman, J., Honza, M., 2002. Are house wren Troglodytes aedon eggs unusually strong? Test of the predicted effect of intraspecific egg destruction. Ibis 144, 57-66.

Pinheiro, J.C., Bates, D.M., 2000. Mixed-effects Models in S and S-Plus. SpringerVerlag, New York.

Rahn, H., Ar, A., 1974. The avian egg: incubation time, water loss and nest humidity. Condor 76, 147-152.

Riczu, C.M., Saunders-Blades, J.L., Yngvesson, A.K., Robinson, F.E., Korver, D.R., 2004 End-of-cycle bone quality in white- and brown-egg laying hens. Poult. Sci. 83, 375-383.

Romanoff, A.L., Romanoff, A.J., 1949. Biochemistry of the Avian Embryo. Wiley, New York.

Shall, R., 1991. Estimation of generalised linear mixed models with random effects. Biometrika 78, 719-727.

Solomon, S.E., 1991. Egg and Eggshell Quality. Wolfe Publishing, Aylesbury, England.

Tuan, R.S., Ono, T., Akins, R.E., Koide, M., 1991. Experimental studies on cultured, shell-less fowl embryos: calcium transport, skeletal development, and cardiovascular functions. In: Deeming, D.C., Ferguson, M.W.J. (Eds.), Egg Incubation: Its Effect on Embryonic Development in Birds and Reptiles. Cambridge University Press, Cambridge, pp. 419-433.

Tucker, G.M., Heath, M.F., 1994. Birds in Europe: Their Conservation Status. BirdLife Conservation Series no. 3. BirdLife International, Cambridge, UK.

Vanderstoep, J., Richards, J.F., 1970. The changes in eggshell strength during incubation. Poult. Sci. 49, 276-285.

Wegner, P., Kleinstäuber, G., Baum, F., Schilling, F., 2005. Long-term investigation of the degree of exposure of German peregrine falcons (Falco peregrinus) to damaging chemicals from the environment. J. Ornithol. 146, 34-54.

Wilkin, T.A., Gosler, A.G., Garant, D., Reynolds, S.J., Sheldon, B.C., 2009. Calcium effects on life-history traits in a wild population of the great tit (Parus major): analysis of long-term data at several spatial scales. Oecologia 159, 463-472. 